\title{
UM PANORAMA ATUAL DA QUÍMICA E DA FARMACOLOGIA DE NAFTOQUINONAS, COM ÊNFASE NA B-LAPACHONA E DERIVADOS
}

\author{
Milton N. da Silva, Vítor F. Ferreira* e Maria Cecília B. V. de Souza
}

Departamento de Química Orgânica, Instituto de Química, Universidade Federal Fluminense, Outeiro de S. João Batista, s/n, 24020-150 Niterói - RJ

Recebido em 15/5/02; aceito em 18/11/02

\begin{abstract}
AN OVERVIEW OF THE CHEMISTRY AND PHARMACOLOGY OF NAPHTHOQUINONES WITH EMPHASIS ON $\beta$-LAPACHONE AND DERIVATIVES. Naphthoquinones have been extensively studied due to their activity as topoisomerase inhibitors. These enzymes are critical to DNA replication in cells. In addition, naphthoquinones have been shown to induce what are known as "reactive oxygen species" that can cause damage to cells. $\beta$-Lapachone is a very important pyranaphthoquinone obtained from the heartwood of the lapacho tree, Tabebuia avellanedae Lorentz ex. Griseb. (Bignoniaceae), and other Tabebuia trees native to Central and South America and chemically from lapachol. $\beta$-Lapachone has a diversity of useful biological activities against various cancer cell lines such as human ovarian and prostate tumors and, at lower doses is a radiosensitizer of several human cancer cell lines. It gives rise to a variety of effects in vitro including the inhibition or activation of topoisomerase I an II in a distinct manner from that of other topoisomerase inhibitors. This review intend to discuss some details of the mechanisms of quinone-induced cell damage and death, and we also summarize results of the literature indicating that b-Lapachone may take part in quinone-elicited apoptosis despite the fact that its mechanism of action in vivo and its targets are still unknown.
\end{abstract}

Keywords: beta-Lapachone; naphthoquinone; pyranaphthoquinone; apoptosis.

\section{INTRODUÇÃo}

As quinonas representam uma ampla e variada família de metabólitos de distribuição natural ${ }^{1,2}$. Nos últimos anos intensificouse o interesse nestas substâncias, não só devido à sua importância nos processos bioquímicos vitais, como também ao destaque cada vez maior que apresentam em variados estudos farmacológicos. $\mathrm{Na}$ natureza, estão envolvidas em etapas importantes do ciclo de vida de seres vivos, principalmente nos níveis da cadeia respiratória e da fotossíntese, como por exemplo as ubiquinonas (1a) e as plastoquinonas $(\mathbf{1 b})^{3}$. As naftoquinonas, por exemplo as vitaminas do tipo $\mathrm{K}(\mathbf{2})$, de irrestrita necessidade aos seres vivos ${ }^{4}$, possuem ação controladora da coagulação sanguínea.

De um modo geral, as quinonas naturais mais representativas são de vital importância para vegetais superiores, artrópodes, fungos, liquens, bactérias, algas e vírus. A distribuição dessas substâncias nos variados organismos implica, possivelmente, em funções biológicas múltiplas, agindo de forma conspícua em seus diversos ciclos bioquímicos.

Em estudos farmacológicos as quinonas mostram variadas biodinamicidades, destacando-se, dentre muitas, as propriedades microbicidas, tripanossomicidas, viruscidas, antitumorais e inibidoras de sistemas celulares reparadores, processos nos quais atuam de diferentes formas. Como exemplo, destaca-se o estresse oxidativo que provocam, ao induzirem a formação deletéria endógena de espécies bioativas derivadas do oxigênio $\left({ }^{1} \mathrm{O}_{2}, \mathrm{OH}, \mathrm{O}_{2}{ }_{2}^{-} \text {e } \mathrm{H}_{2} \mathrm{O}_{2}\right)^{5}$, como ocorre no Trypanosoma cruzi, agente causador da doença de Chagas. Outra atividade marcante destas substâncias, descoberta um tanto recentemente, é a inibição do complexo das topoisomerases, ação que provoca o desencadeamento da apoptose celular (suicídio celular). A interferência das quinonas na apoptose constitui-se hoje em

\footnotetext{
*e-mail: cegvito@vm.uff.br
}

pesquisa interdisciplinar de fronteira na química medicinal, existindo grande expectativa quanto à delineação de estratégias racionais visando o combate de neoplasias, principalmente as relacionadas ao câncer de próstata.

Com base na sua estrutura molecular, as quinonas são divididas em diferentes grupos, utilizando-se como critério o tipo de sistema aromático que sustenta o anel quinonoídica: benzoquinonas - um anel benzênico; naftoquinonas - um anel naftalênico; antraquinonas - um anel antracênico linear ou angular (Figura 1).

De modo muito peculiar, em decorrência de diferentes arranjos quinonoídicos (isomeria), com um mesmo tipo de anel pode-se ter, dependendo das disposições relativas das carbonilas, diferentes quinonas. Por exemplo, no arranjo de base naftalênica tem-se a forma isomérica 1,2 ou orto-quinonoídica, quando as carbonilas são vizinhas (4a, Figura 1), ou a 1,4, para-quinonoídica, com as carbonilas tendo entre si dois carbonos (4b). Outros arranjos

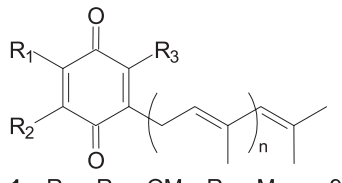

1a, $R_{1}=R_{2}=O M e, R_{3}=M e, n=9$ 1b, $R_{1}=R_{2}=M e, R_{3}=H, \quad n=9$<smiles>O=C1c2ccccc2C(=O)c2ccccc21</smiles>

3

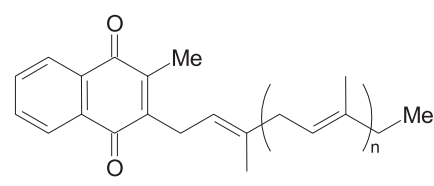<smiles>CC1(C)CCC2=C(O1)c1ccccc1C(=O)C2=O</smiles>

$\beta$-Lapachona (4a) orto-Naftoquinona<smiles>CC1(C)CCc2c(oc3c2C(=O)c2ccccc2C3=O)C1</smiles>

$\alpha$-Lapachona (4b) para-Naftoquinona
Figura 1. Classificação e formas isoméricas para-quinonoídica e ortoquinonoídica 
isoméricos são conhecidos, principalmente em sistemas policíclicos, nos quais os distanciamentos entre as carbonilas podem ser maiores. Estas formas isoméricas diferem muito em suas propriedades físicas, químicas e quanto à sua atuação biológica. Um exemplo típico é a orto-naftoquinona, $\beta$-lapachona $\mathbf{4 a}$, do grupo das tabebuias, que é muito mais ativa contra o Trypanosoma cruzi que o seu isômero natural 4b, $\alpha$-lapachona (Figura 1).

Numa observação mais apurada sobre a importância das quinonas, especialmente de benzoquinonas, naftoquinonas e antraquinonas, pode-se citar o grande número de drogas neste grupo que possuem aplicações práticas reconhecidas. Algumas, inclusive, chegaram à produção industrial, como por exemplo, as vitaminas $\mathrm{K}^{6}$, as mitomicinas e as antraciclinas. Sob o ponto de vista estrutural, em grande parte destacam-se nestas substâncias anéis redox acoplados a diversos sistemas heterocíclicos, normalmente nas posições 2,3 ou 3,4 do sistema naftalênico. Estes anéis heterocíclicos podem ser dos tipos furânico, pirânico, pirrólico, etc. indicando sua importância na expressão da bioatividade.

A química das quinonas, já há muito vem sendo descrita em vários livros publicados ${ }^{7}$, em inúmeras e excelentes revisões, estando assim bem documentada sua evolução ao longo do tempo.

Neste artigo de divulgação, enfocaremos as mais importantes naftoquinonas naturais e sintéticas citadas nos últimos anos na literatura científica, descrevendo-as separadamente nos itens que se seguem. Em especial, serão discutidos os aspectos biológicos e sintéticos da $\beta$-lapachona (4a), uma substância que vem tendo destacada e acentuada atuação, tanto na química quanto na farmacologia.

As mitomicinas são quinonas de atividade antibiótica e antitumoral, de uso clínico reconhecido, produzidas por culturas de alguns fungos. A mitomicina $\mathrm{C}^{8}(\mathbf{5})$, a mais conhecida do grupo, foi isolada de cultura de Streptomyces caespitosus (Figura 2) sendo utilizada na quimioterapia de certos tipos de tumores sólidos ${ }^{9,10}$. Em trabalho recente, Alves e Oliveira revisaram os mais importantes aspectos químicos e farmacológicos desta classe de substâncias ${ }^{11}$.

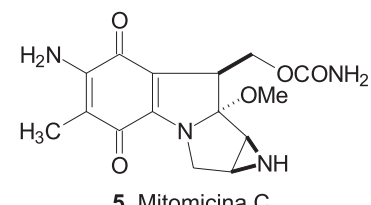

Figura 2. Mitomicinas antitumorais que atuam por bioativação redutiva

As antraciclinas representam uma classe de quinonas antibióticas proveniente de culturas de fungos Streptomyces. Os representantes mais conhecidos desta classe são a daunorubicina (7a) e a adriamicina (7b) (Figura 3) isoladas de S. peucenticus e S. coeruleorubidus, respectivamente. A daunorubicina (7a) também possui efeito terapêutico contra a leucemia humana ${ }^{12}$. Uma única citação descreve esta substância como inibidora de Trypanosoma rhodiens ${ }^{13}$. Estudos sobre seu modo de atuação antimicrobiano indicam que estão envolvidas na formação de um complexo com as bases purínicas e pirimidínicas provocando a inibição da síntese do DNA. As substâncias 7a e $\mathbf{7 b}$ também são ativas
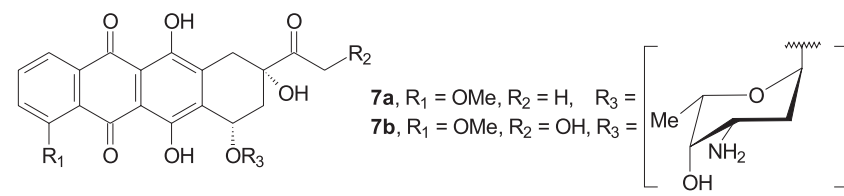

Figura 3. Exemplos de antraciclinonas com atividades antibióticas contra o sarcoma 180, o carcinoma ascítico de Ehrlich e outros tipos de carcinomas ${ }^{14}$. Outros estudos sobre o mecanismo de atuação biológica destacam a importância do grupo quinonoídico como o grupo farmacofórico imprescindível para a biorreatividade no nível das enzimas do tipo redutases, formando espécies reativas do oxigênio que induzem a apoptose ${ }^{15-18}$.

Atualmente, há um grande interesse pelo conhecimento da farmacologia e do modo de atuação destas substâncias, como pode ser demonstrado pelo número de crescente de publicações sobre o mecanismo de atuação da $\beta$-lapachona. O progresso quanto aos conhecimentos da bioquímica das atividades enzimáticas, além dos recentes avanços da química computacional, em muito pode contribuir para o esclarecimento em maior profundidade dos mecanismos de atividade de fármacos e, em consequiência, para o planejamento de novas drogas comerciais. O contexto de previsibilidade que estes estudos trazem auxiliam na busca de agentes antineoplásicos baseados em planejamentos racionais ${ }^{19}$, resultando na obtenção de substâncias com maior seletividade e eficiência antineoplásica.

A citotoxicidade das quinonas leva à especulação de que existe uma propriedade química intrínseca na unidade quinonoídica, associada com outros fatores estruturais, que são responsáveis pela intensidade das atividades antitumorais ${ }^{20}$. Uma possibilidade plausível é a capacidade das quinonas se reduzirem pelas flavoenzimas celulares $^{21}$. Foi observado que muitas quinonas possuem um grupo de saída que pode ser ativado por redução das carbonilas quinonoídicas, gerando intermediários alquilantes ${ }^{22}$ (agentes antineoplásicos biorredutores). Atualmente, existem sólidas evidências de que este mecanismo de ação é o que mais se aproxima das ações farmacológicas das mitomicinas e antraciclinas ${ }^{23}$.

A quimioterapia baseada num planejamento racional de fármacos tem, então, no sistema redox das quinonas um bom modelo para estudos teóricos. Um dos poucos estudos desta natureza foi realizado com um grupo de 65 quinonas naturais e sintéticas, onde procurou-se relacionar a atividade antimalárica com a energia livre de Gibbs de oxi-redução. De conclusivo, verificou-se que há, de fato, uma relação da expressão da atividade biológica com valores baixos de $\Delta \mathrm{G}^{0}$ (menores que $\left.+8 \mathrm{Kcal}\right)^{24,25}$.

\section{NAFTOQUINONAS}

Dentre as naftoquinonas naturais destaca-se o lapachol (8) que pode ser considerado um dos principais representantes do grupo de quinonas das tabebuias. É conhecido desde $1858^{26}$ e desde então, através dos séculos ${ }^{27}$, tem sido encontrado como constituinte de várias plantas das famílias Bignoniaceae, Verbenaceae e Proteaceae. Entretanto, sua ocorrência é maior na família Bignoniácea, particularmente no gênero Tabebuia (Tecoma), juntamente com outras quinonas heterocíclicas não menos importantes do grupo ${ }^{28}$. O lapachol (8) é de fácil extração da serragem da madeira ${ }^{29}$ de várias espécies de ipê, plantas do Brasil e da fronteira com a Argentina. Há no Brasil cerca de 46 tipos de madeiras comerciais conhecidas como "ipês" (Tabebuia sp). Atualmente são exportados pela empresa PVP Sociedade Anônima (Parnaíba, Piauî ${ }^{30}$ ) ao custo de US\$1.200/kg. Outrora, o lapachol foi comercializado para utilização como coadjuvante no tratamento de certos tipos de câncer, sendo o medicamento fabricado pelo Laboratório Farmacêutico do Estado de Pernambuco (LAFEP), não mais disponível no mercado. Esta naftoquinona também já constou do catálogo da Aldrich Chemical Co., em edição antiga (1989). Curiosamente, também não consta de qualquer das últimas edições do Índice Merck.

Em se tratando de quinonas obtidas das tabebuias, não se poderia deixar de mencionar o pioneirismo dos estudos farmacológicos realizados no Brasil por O. G. de Lima (UFPe) na década de 60 e o 
do Prof. B. Gilbert (UFRJ), a partir da década de 70, do século passado. Desde então, vários outros pesquisadores, como o Prof. A. V. Pinto, do NPPN-UFRJ, desenvolvem pesquisas com este grupo de naftoquinonas e seus derivados semi-sintéticos, em estudos farmacológicos e químicos de diversos tipos. Mais recentemente, o grupo da Profa. M. O. F. Goulart (UFAl) dedica-se ao estudo eletroquímico destas quinonas.

O principal interesse no lapachol $(\mathbf{8})$ reside em sua capacidade de induzir o estresse oxidativo através da formação intracelular de espécies reativas do oxigênio, como o peróxido de hidrogênio $\left(\mathrm{H}_{2} \mathrm{O}_{2}\right)$, o ânion-radical superóxido $\left(\mathrm{O}_{2}^{-*}\right)$ e o radical hidroxila (HO*). Estas espécies podem danificar alguns componentes celulares importantes, tanto de células normais como de malignas. Esta interferência xenobiótica altera o balanço natural de sinais que interferem na divisão celular em pontos específicos da evolução morfogênica natural ("checkpoint" ou ponto de checagem ${ }^{31}$ ). A alteração da normalidade pode induzir a apoptose como alternativa, caso não se consiga eliminar por completo o estresse oxidativo ${ }^{32}$. Similar metodologia, no que diz respeito à geração de espécies reativas do oxigênio, se baseia a terapia fotodinâmica, onde estas espécies são geradas por interação de luz de comprimento de onda adequado com um fotossensibilizador e oxigênio, capazes de induzir a inviabilização de células ${ }^{33}$.

Apesar de possuir estágios de atuação biológica não muito conhecidos, o lapachol (8) deve atuar por diferentes mecanismos. É interessante observar que, em relação à quimioterapia, há um aparente antagonismo de atuação do lapachol (8), que age no fenômeno da apoptose sobre células do câncer, as quais, ao contrário, possuem crescimento desordenado ${ }^{34,35}$.

O lapachol (8) foi avaliado clinicamente nos tratamentos de carcinoma $^{36}$ de Walker-256 e do sarcoma de Yoshida ${ }^{37}$. Embora promova a regressão definitiva de neoplasias em aproximadamente $30 \%$ dos portadores destas patologias, além de agir como analgésico, os ensaios clínicos o desaprovam em decorrência de efeitos colaterais que, em muito, agravam o quadro clínico de pacientes com câncer: anemia, aumento do tempo de coagulação e problemas gastrintestinais $^{38}$. Recentemente, o 5-hidroxi-lapachol isolado de Tectona grandis mostrou-se mais tóxico que o próprio lapachol $(\mathbf{8})$, em teste de letalidade com Artemia salina ("brine shrimp") ${ }^{39}$, suscitando a possibilidade de uma boa tolerância por exigir doses menores para a ação farmacológica desejada.

Estudos realizados indicam que o estresse oxidativo induzido pelo lapachol (8) ocorre no nível da enzima P450 redutase. Neste processo as espécies reativas do oxigênio promovem a cisão do $\mathrm{DNA}^{40}$. Este tipo de mecanismo de ação é importante, pois alguns microorganismos patogênicos são muito mais sensíveis ao estresse oxidativo que os humanos hospedeiros ${ }^{41}$.

Muitas outras atividades farmacológicas foram atribuídas ao lapachol (8) e a seus derivados semi-sintéticos, tais como atividade antimicrobiana e antifúngica ${ }^{42}$; atividade cercaricida (prevenção da penetração de cercárias Schistosoma mansoni na pele) $)^{43}$; ação moluscicida (atividade contra caramujos Biomphalaria glabrata, hospedeiro intermediário do Schistosoma mansoni ${ }^{44}$ ); leishmanicida [ação intracelular nas formas amastigotas de Leishmania (viannia) braziliensis $]^{45,46}$; tripanossomicida ${ }^{47,48}$ (atividade contra o Trypanosoma cruzi, que é o agente causador da doença de Chagas em sua fase tripomastigota); antimalárico (atividade contra eritrócitos parasitados por Plasmodium falciparum ${ }^{49}$ ); uso contra enteroviroses ${ }^{50}$; antiinflamatória $^{51}$; antineoplásica ${ }^{52}$ e antiulcerantes ${ }^{53}$. Há ainda relatos da forte atividade anticonceptiva em ratas, que causou $100 \%$ de mortalidade fetal/embrião sem, contudo, causar aparente efeito tóxico aos animais ${ }^{54,55}$.

$\mathrm{Na}$ busca de agentes antimaláricos potenciais, tendo como protótipo as vitaminas $\mathrm{K}$ e o próprio lapachol $(\mathbf{8})$, foi feito um estudo com diversos análogos sintéticos. A substância 9 foi uma das que apresentou melhor atividade em pacientes infectados por Plasmodium vivae, parasita causador da malária ${ }^{56}$. Uma das substâncias deste grupo, a atovacona 10, encontra-se no estágio de testes da fase clínica ${ }^{57}$. Esta quinona é uma inibidora da enzima diidroorotato desidrogenase (EC 1.3.99.11) que catalisa a síntese do monofosfato de uridina nos $\operatorname{parasitas}^{58}$ (Figura 4).

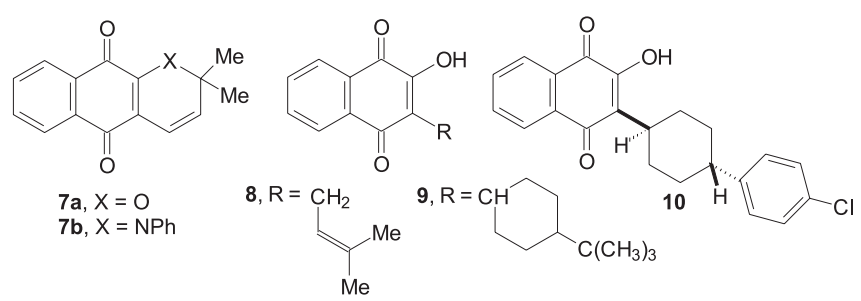

Figura 4. Xiloidonas (7a,b), lapachol (8) e congêneres

Outros exemplos interessantes são as substâncias 11a-d, de significativa atividade contra o vírus HIV-1, agindo especificamente nas enzimas proteases (Figura 5) ${ }^{59}$.

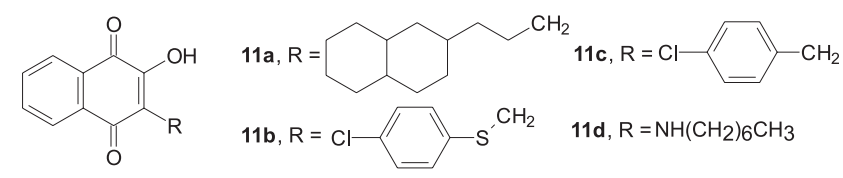

Figura 5. Derivados de 2-hidróxi-naftoquinonas anti HIV-1

\section{NAFTOQUINONAS PIRÂNICAS}

O lapachol (8, Figura 4) foi matéria prima para as sínteses de muitas outras substâncias de distintas biodinamicidades. As mais ativas foram os derivados contendo os anéis pirânicos e furânicos, por exemplo, a xiloidona 7a, a $\beta$-lapachona (4) ${ }^{60}$ e muitas outras naftoquinonas, como a 1-aza-antraquinona $7 \mathbf{b}^{61}$ sintetizada recentemente. A quinona natural xiloidona (7a), de atividade antimicrobiana, pode ocorrer também como artefato de origem fotoquímica durante o isolamento do lapachol $(\mathbf{8})^{62}$.

A $\beta$-lapachona (4a) tem sido encontrada como constituinte minoritário durante o isolamento de outras naftoquinonas ${ }^{63}$ do cerne das árvores de ipês, como por exemplo Tabebuia avellanedae Lorentz ex. Griseb. (Bignoniaceae), nativa das Américas Central e do Sul. Tal qual o lapachol (8), esta orto-piranonaftoquinona mostra uma diversificada ação farmacológica ${ }^{64}$ envolvendo principalmente o ciclo redox.

\section{ATIVIDADE FARMACOLÓGICA VIA CICLO REDOX}

Como mencionado anteriormente, o principal interesse nas quinonas advém da sua capacidade de induzir o estresse oxidativo nas células. Esse estresse pode também resultar da ação de muitos agentes ambientais tóxicos sobre seres vivos, como radiações gama e ultravioleta, ozônio e poluentes automotivos no ar, assim como de certas substâncias da cadeia alimentar e de derivados do tabagis$\mathrm{mo}^{65,66}$. Além destes fatores ambientais, estima-se que 1 a $2 \%$ do oxigênio consumido pelos mamíferos sejam convertidos a $\mathrm{O}_{2}{ }^{-\bullet} \mathrm{e}_{2} \mathrm{O}_{2}$, devido a falhas fisiológicas na mitocôndria permitindo que elétrons escapem sem que sejam transferidos pelo oxigênio ${ }^{67}$. Segundo Kubota 
e outros autores, o desequilíbrio entre a formação e a remoção dos radicais livres no organismo, decorrente da diminuição dos antioxidantes endógenos ou do aumento da geração de espécies oxidantes, leva a um estado pró-oxidante que favorece a ocorrência de lesões oxidativas em macromoléculas e estruturas celulares que podem provocar a morte celular ${ }^{68,69}$.

Muitas pesquisas na área de doenças endêmicas, empregando triagens com quinonas, foram realizadas na busca de substâncias com atividade tripanossomicida. Estes estudos exploraram a capacidade das quinonas induzirem o estresse oxidativo conforme esboçado no Esquema 1, que apresenta resumidamente as etapas bioquímicas deste processo, concebidas por diversos autores nos últimos $30 \operatorname{anos}^{1,70,71}$.

Neste esquema, sob ação enzimática, um substrato quinonoídico reduz-se com um elétron para formar o ânion semiquinona (Q*), catalisada pelas enzimas flavinas NADPH citocromo P-450 redutase (E.C. 1.6.2.3), NADPH citocromo b5 redutase (E.C. 1.6.2.2) ou NADPH ubiquinona oxidoredutase (E.C. 1.6.5.3). A cinética desta redução depende de vários fatores, incluindo o potencial de redução da quinona. Uma vez formada a espécie semiquinona Q*, esta reduz o oxigênio molecular ao ânion-radical superóxido $\left(\mathrm{O}_{2}^{-\cdot}\right)$ que, na presença da enzima superóxido dismutase (SOD, E.C. 2,55,56), é transformado em $\mathrm{H}_{2} \mathrm{O}_{2}$. Este ânion-radical superóxido $\left(\mathrm{O}_{2}^{-*}\right)$, por catálise com metais de transição (reação de Fenton ${ }^{72}$ ), ou por reação com $\mathrm{H}_{2} \mathrm{O}_{2}$ (reação de Harber-Weiss ${ }^{73}$ ), gera $\mathrm{HO}^{*}$ no interior da célula. Embora $\mathrm{o}_{2} \mathrm{O}_{2}$ não seja um radical livre, é uma substância bastante reativa, podendo promover também a oxidação de algumas biomoléculas (Esquema 1). Em resumo, $\mathrm{HO}^{*} \mathrm{e}_{2} \mathrm{O}_{2}$ são as principais espécies responsáveis pelo estresse oxidativo celular.

$\mathrm{Fe}(\mathrm{II})+\mathrm{H}_{2} \mathrm{O}_{2} \rightarrow \mathrm{Fe}(\mathrm{III})+\mathrm{HO}^{-}+\mathrm{HO}^{*}$ (reação de Fenton)

$\mathrm{O}_{2}^{-}+\mathrm{H}_{2} \mathrm{O}_{2} \rightarrow \mathrm{O}_{2}+\mathrm{HO}^{-}+\mathrm{HO}^{-}$(reação de Haber-Weiss)

Na tentativa de eliminar estas espécies oxidantes, as células desencadeiam mecanismos de desintoxicação, através dos agentes antioxidantes intracelulares. Uma perfeita eliminação e/ou conseqüente controle do estresse oxidativo vai depender, em muito, dos níveis dos agentes intracelulares antioxidantes, como $\alpha$-tocoferol, vitamina $\mathrm{C}$, enzimas superóxido dismutase (SOD), catalase (CAT), glutationa redutase (GSH) e glutationa peroxidase (GPX). Em sistemas onde ocorre uma persistência do ciclo redox, ou então faltam mecanismos de proteção, há aumento intracelular dos oxidantes $\mathrm{O}_{2} \cdot-\mathrm{e} \mathrm{H}_{2} \mathrm{O}_{2}$, promovendo a danificação de componentes celulares vitais como as membranas, através da peroxidação dos lipídios e a diminuição da capacidade antioxidante celular. Desta forma, a espécie radicalar $\mathrm{HO}^{\circ}$, gerada por uma reação tipo Fenton, em que $\mathrm{H}_{2} \mathrm{O}_{2}$ é reduzida por $\mathrm{Fe}^{+2}$ ou $\mathrm{Cu}^{+1}$ (esta participação ainda é polêmica ${ }^{74}$ ) pode danificar o genoma. Sua atuação leva a consequiências adversas, por alteração do sinal da transcrição na expressão de genes, mutagenicidade e/ou por ativação de fatores responsáveis pela indução da apoptose. A formação, em meio biológico, do radical hidroxila mediada por metais, ainda constitui matéria controversa na literatura ${ }^{75}$.

Beckman e Ames estimam que a degradação do DNA por HO• pode levar à formação de, aproximadamente, 150.000 subprodutos por célula, resultantes de sua adição ao DNA seguida de clivagem em diversos pontos da cadeia. Calcula-se que o estresse oxidativo seja o responsável pela metade dos cânceres humanos ${ }^{76}$. A adição do radical hidroxila (HO*) na dupla hélice do DNA é rapidíssima, quebrando-a em uma ou duas fitas. $\mathrm{O}$ ataque pelo radical à topologia da macromolécula ocorre nas bases nitrogenadas que são aceptoras de radicais ou se dá nas unidades de carboidratos, resultando em quebra da ligação N-glicosídica.

Embora muito complexo, com etapas ainda desconhecidas, o ciclo redox continua sendo a ferramenta atual de que se valem os farma- cologistas para obter conhecimentos sobre a ação citotóxica das naftoquinonas. No estudo do ciclo redox o T. cruzi tem sido o modelo experimental mais utilizado até o momento.

Em resumo, uma série de processos de importância crucial para as células, como a indução da apoptose e os danos provocados pelo estresse oxidativo estão entre os principais efeitos que as quinonas provocam em sistemas biológicos. Ao que parece, as espécies $\mathrm{O}_{2}{ }^{-} \mathrm{e}$ $\mathrm{H}_{2} \mathrm{O}_{2}$ estão sendo consideradas como dois importantes sinais reguladores de condições intracelulares. Acredita-se que o aumento de suas concentrações (condições mais oxidantes) favoreça a apoptose.

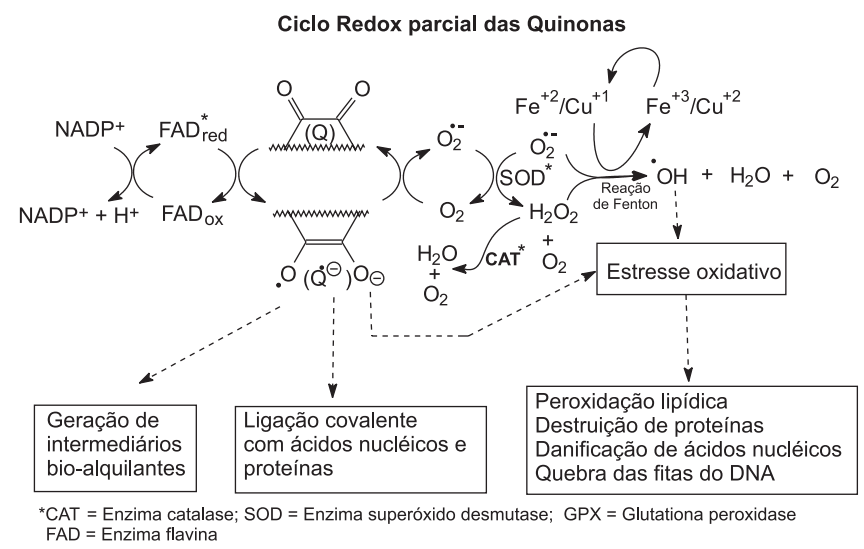

Esquema 1. Ciclo redox induzido por quinonas

\section{APOPTOSE VIA INIBIÇÃO DAS TOPOISOMERASES I E II}

As enzimas nucleares topoisomerases I (EC\# 5.99.1.2) e II (EC\# 5.99.1.3) são críticas para o funcionamento normal de qualquer célula. São elas que mantêm a integridade do DNA, reparando-o quando danificado. Nos organismos mais simples, quando em ação reparadora, as topoisomerase I ligam-se a uma ou duas fitas do DNA, mas introduzem um só corte numa das fitas do DNA. Organismos superiores possuem, além da topoisomerase I, a topoisomerase II, que se complexam com duas fitas do DNA e induzem dois cortes durante o processo de reparação. As enzimas topos I e II têm funções recíprocas reversas, ou seja, uma é expressa quando a outra é inibi$\mathrm{da}^{77}$. Ambas cortam o DNA por ataque a pontos de unidade tirosínica, na ligação fosfodiéster do DNA e são críticas para o bom funcionamento celular. Qualquer alteração no balanço entre estas enzimas é suficiente para induzir a apoptose. Ressalte-se que micromoléculas, como a actinomicina-D, a daunomicina e a adriamicina, também atuam diretamente no DNA, mas por intercalação entre nucleotídios vicinais da fita do DNA, via interações de van der Waals e iônicas. Deste modo, a intercalação interfe nas funções normais do DNA, bloqueando as polimerases e interferindo na síntese de proteínas ${ }^{78}$.

Em sua ação natural, estas topoisomerases assentam-se na estrutura do DNA por uma supertorção (dobras) topológica, quando fazem cortes, permitindo que as funções de transcrição, reparação, replicação e estruturação do cromossomo ocorram normalmente. Após esta abertura, as células dividem-se seguindo uma série de etapas bem definidas (G1, G2 e M). Na primeira, chamada de G1, a célula copia o DNA para os seus cromossomos num estágio conhecido como síntese (ou $\mathbf{S}$ ). A célula divide-se, e um segundo conjunto idêntico de cromossomos vai para a célula-filha (metáfase $\mathbf{M}$ ), sendo este estágio chamado de mitose. Durante cada estágio da divisão, a célula possui um compasso de espera, ponto de checagem, quando então faz uma auto-avaliação do novo conjunto de cromossomos, 
conferindo se é realmente idêntico ao antigo. Se por acaso a avaliação não for favorável, o processo de divisão é colocado em modo inercial à espera do reparo. Se o dano no cromossomo for muito grande, sem possibilidades de reparo a contento, a célula, na tentativa de se preservar, interrompe o seu ciclo vital cometendo suicídio. Acredita-se que esta seja uma estratégia de proteção dos organismos, que assim evitam passar o dano para uma nova geração de células.

Nas células cancerosas não existem os pontos de checagem G1, G2 e M e isto evita sua apoptose mesmo tendo ocorrido um acúmulo de danos genéticos. Uma estratégia de combate às células cancerosas seria o uso de substâncias que induzissem a formação de pontos artificiais de checagem no processo da divisão celular. Se assim ocorrer, haverá a indução da morte das células malignas. Nestas condições, qualquer agente (ou inibidor) que afete nas neoplasias o complexo topoisomerase-DNA poderia induzir este processo letal. Como as células cancerígenas crescem e se multiplicam com rapidez, estarão mais sensíveis aos inibidores da topoisomerase I que as células normais. Portanto, estas enzimas são alvos especiais na nova quimioterapia antitumoral.

As substâncias que atuam nas topoisomerases podem ser divididas em duas classes: 1) estabilizadoras do complexo topoisomeraseDNA e 2) inibidoras catalíticas da topoisomerase ${ }^{79}$. Já existem várias substâncias que pertencem às duas categorias. Os inibidores das topoisomerases I e II pelo mecanismo 1 são mais numerosos, como por exemplo o alcalóide quinolínico camptotecina (12), isolado de Camptotheca acuminata, e seu análogo sintético, a topotecan $(\mathbf{1 3})^{80}$, drogas em fase de ensaios clínicos, dentre outras (Figura 6).

Os inibidores da topoisomerase estabilizam o complexo enzimaDNA após o estágio do corte e antes do DNA ser recomposto. Portanto, o DNA e a enzima não podem prosseguir com suas funções normais. Esta nova abordagem na quimioterapia do câncer ainda requer mais subsídios que permitam delinear estratégias, de modo a fazer com que células malignas percam a habilidade de se reparar, induzindo a apoptose ${ }^{81}$. Um problema desta quimioterapia e, de um modo geral, de todas até hoje conhecidas, é a possibilidade das células cancerosas se tornarem resistentes aos inibidores de topoisomerase, via um mecanismo conhecido como resistência a múltiplas substâncias ("multi-drug resistance" ou MDR), aspecto bioquímico complexo e ainda em estudo.
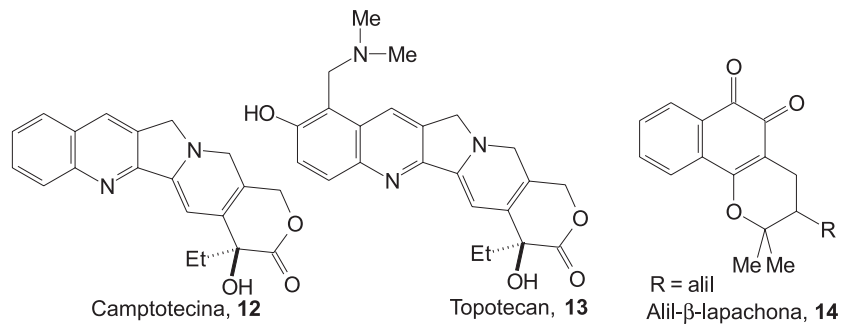

Figura 6. Substâncias inibidoras da enzima topoisomerase I

Para um efeito citotóxico sinergístico ambas as enzimas topoisomerases devem ser inibidas ${ }^{82}$. Nos humanos são conhecidos três tipos de topoisomerases - I, II $\alpha$ e II $\beta$ - produzidas por três tipos de cromossomos. A II $\alpha$ está presente em todos os seres eucarióticos, enquanto que apenas os vertebrados possuem a II $\beta$. Esta última é o homólogo superior da II $\alpha$, com pequenas diferenças, sendo expressa quando II $\alpha$ é inibida. Parece que II $\beta$ é um tipo de "back-up" de II $\alpha$ para a célula, e está mais associada à diferenciação celular do que à proliferação. Atualmente o etoposídeo (15a) é a substância inibidora mais promissora com este mecanismo de ação (Figura 7).
Várias substâncias estão relatadas na literatura como tendo atividade inibidora da topoisomerase II: a $\beta$-lapachona (4a) (detalhes adiante), a elipticina (15b) e diversos derivados, e as quinonas saintopina (16a) e eleuterina (16b), mostradas na Figura 7.<smiles>CCOC(=O)c1cc(O)cc(O)c1C(=O)c1cc(O)c2c(c1)C(=O)c1cc(O)cc(O)c1-2</smiles><smiles>CCCCCCn1c2ccccc2c2c(C)c3cnccc3c([Nb])c21</smiles>

Figura 7. Substâncias com exclusiva atividade inibidora da topoisomerase II

A inibição da topoisomerase II é mais desafiadora, pois foge um pouco ao modelo clássico no qual um ligante interage com um receptor. Na inibição da topo II há uma interação simultânea com dois receptores ${ }^{83}$. Esta inibição pode ocorrer por uma interação da região aromática dos agentes com as bases do DNA ou de regiões mais polares com outros sítios da topoisomerase. É fato que uma simples intercalação ao DNA não explica de todo a inibição do complexo topoisomerase-DNA. De forma simplificada, a Figura 8 mostra a formação dos complexos topoisomerases I e II com o DNA ${ }^{84}$, seguida da interação com um inibidor que congela o complexo DNATopoisomerase levando à sua fragmentação e, conseqüentemente, à morte celular. A ordem cronológica destes eventos ainda é desconhecida, como já foi destacado anteriormente. Os inibidores não agem na formação do complexo topoisomerase-DNA, ao contrário, eles

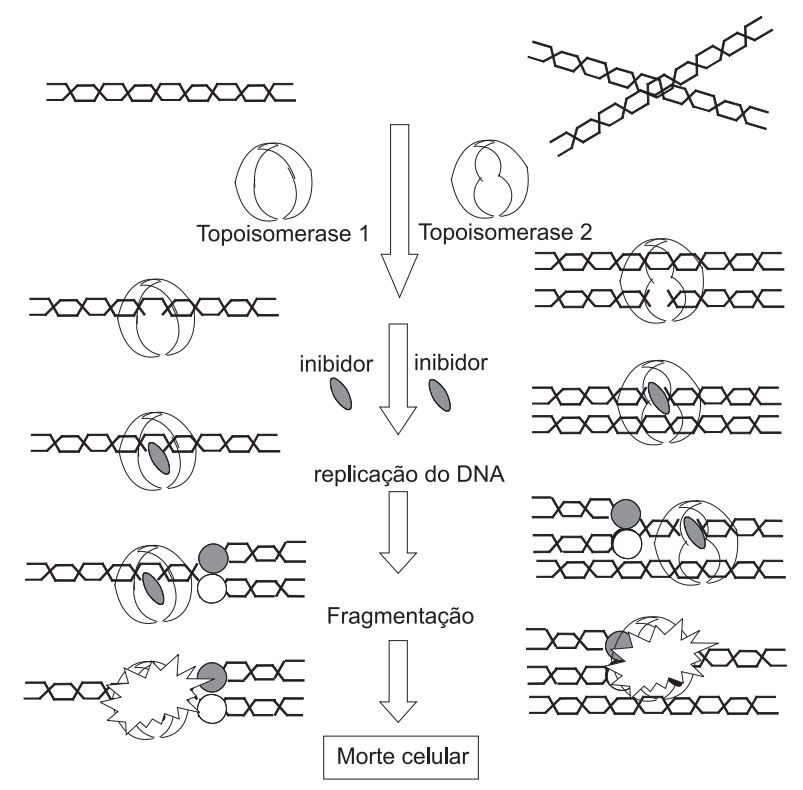

Figura 8. Esboço das alterações nas ações das topoisomerases 
não deixam as topoisomerases reconectarem-se ao DNA e desfazerem o complexo. Eles atuam tal qual uma cola que mantém a topoisomerase ligada ao DNA. Outros fatores celulares percebem o dano e sinalizam a deflagração da apoptose.

Uma segunda classe, não menos importante, de inibidores da topoisomerase corresponde a inibidores catalíticos, que não agem sobre o complexo topo-DNA, mas sim na atividade catalítica das enzimas ${ }^{85}$. Entre os mais estudados encontram-se as bis-2,6dioxopiperazinas (ICRF-159, 17a e ICRF-193, 17b) ${ }^{86,87}$, que inibem a enzima topoisomerase II por bloqueio do sítio catalítico (Figura 9).

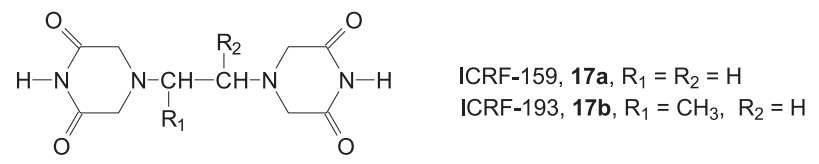

Figura 9. Dioxopiperazinas que bloqueiam o sítio catalítico da enzima topoisomerase II

A $\beta$-Lapachona (4a) exibe in vitro variados tipos de atividade contra diferentes linhagens de células, principalmente células malignas humanas dos cânceres de pulmão, mama, colo-retal, próstata, melanoma e leucemia ${ }^{88,89}$. Apesar do amplo espectro de bioatividades, os mecanismos de atuação da $\beta$-lapachona (4a) em modelos experimentais ainda não estão bem delineados. O que se sabe decorre de estudos abordando a atuação tripanossomicida. Neste modelo, além do estresse oxidativo também se observam vias biorredutivas alquilantes sobre ácidos nucléicos e/ou proteínas ${ }^{90,91}$. Outras atividades farmacológicas foram atribuídas a esta quinona, podendo-se destacar as atividades antibacteriana e antifúngica ${ }^{92}$, cercaricida e antipsoriática $\left(\mathrm{IC}_{50} 0,7 \mu \mathrm{M}\right.$ contra queratinocite HaCaT humana) $)^{93}$.

A $\beta$-lapachona (4a) também age como inibidora das topoisomerases $\mathrm{I}^{94}$ e II $^{95}$. A incubação direta desta substância com a topoisomerase I, antes da adição de DNA como substrato, aumenta drasticamente o efeito inibitório, sugerindo a interação direta da $\beta$ lapachona com a topoisomerase I. Também foi verificado que esta ação depende da presença de NQO1-redutase. Este modo de atuação difere em relação ao de outras substâncias inibidoras das topoisomerases, como por exemplo ${ }^{96}$ a camptotecina $(\mathbf{1 2})^{97}$ e o topotecan (13). Entretanto, a atuação inibitória da $\beta$-lapachona (4a) sobre sistemas reparadores parece não ser o seu único modo de atuação, uma vez que fungos que não expressam topoisomerase I também são inibidos por esta quinona. Ao que parece, a $\beta$-lapachona (4a) é um xenobiótico de atuação crítica sobre mais de um alvo intracelular, que não só a topoisomerase I. Uma outra hipótese alternativa seria o ataque pela $\beta$-lapachona (4a) a pontos específicos do ciclo catalítico que expressa a ação da topoisomerase I como, por exemplo, a pontos de checagem G1 e S, por ação outra que não a de uma simples intercalação. Recentemente, foi relatado que a $\beta$-lapachona (4a) e a camptotecina (12) induzem a apoptose de células malignas epiteliais, de glioma humano, e de pigmentos retinais humanos. As duas drogas atuam sobre a topoisomerase I, mas por vias diferentes ${ }^{98}$. A $\beta$ lapachona (4a) também induz a apoptose de células do câncer de mama dos tipos MCF-799 e T47D ${ }^{100}$.

Há um forte interesse voltado ao uso comercial da $\beta$-lapachona (4a), que pode ser demonstrado pelas diversas patentes concedidas ao longo dos últimos anos envolvendo esta quinona, provavelmente como garantias de uso comercial futuro. Também há muitas patentes relacionadas às sínteses de alguns derivados naftoquinônicos com estruturas similares ${ }^{101}$.

Deve-se frisar que a ação indutora da $\beta$-lapachona (4a) no processo de apoptose tem despertado algumas controvérsias ${ }^{102}$. Alguns acreditam que esta quinona não atue sobre o complexo topoisomeraseDNA do modo como vinha sendo proposto por muitos autores. Kuo e colaboradores ${ }^{103}$, por exemplo, mostraram que a $\beta$-lapachona (4a) promove a elevação dos níveis de $\mathrm{H}_{2} \mathrm{O}_{2}$ e $\mathrm{O}_{2}{ }^{\cdot-}$ (estresse oxidativo) em células de leucemia HL-60 induzindo, por conseqüência, a apoptose em estágios posteriores. De fato, a favor disto está o antagonismo entre a atividade da $\beta$-lapachona (4a) e a da vitamina $C$ (antioxidante), que não ocorre nas presenças de outros inibidores de topo I e II, ou seja, enquanto a $\beta$-lapachona gera radicais livres, a vitamina $\mathrm{C}$ os captura. Entretanto, estes autores não descartam totalmente a possibilidade de uma atuação paralela e direta da $\beta$-lapachona sobre as enzimas topos I e II. O mesmo grupo demonstrou ${ }^{104}$ que a indução da apoptose pode estar relacionada com o aumento dos níveis de $\mathrm{H}_{2} \mathrm{O}_{2}$ celular catalisado por $\mathrm{NAD}(\mathrm{P}) \mathrm{H} /$ quinona oxidorredutase. No estudo realizado, foi observado um aumento significativo deste agente oxidante em células de leucemia HL-60 incubadas com $1 \mathrm{mM}$ de $\beta$ lapachona. Portanto, não se deve descartar de todo a importância do ciclo redox na apoptose, tendo em vista sua dependência da enzima $\mathrm{NAD}(\mathrm{P}) \mathrm{H}$ /quinona oxirredutase (NQO1), que reduz a função quinona, via transferência de dois elétrons. Mais recentemente, o mesmo grupo também mostrou que a $\beta$-lapachona age em células de osteocarcinoma humano (U2-OS) por necrose celular independente do estresse oxidativo, e não por apoptose, indicando que o seu mecanismo de atuação está relacionado também com o tipo de célula cancerígena $^{105}$

Boothman e colaboradores mostraram evidências que indicam a participação da enzima NQO1 no processo de ativação da $\beta$-lapachona (4a) na apoptose, aumentando a citotoxicidade ${ }^{106}$. A NQO1 é expressa em maior grau em vários tipos de tumores, incluindo os de mama, pulmão e do colo-retal, do que em tecidos normais. Esta observação pode se constituir em uma nova estratégia para a quimioterapia de alguns tipos de câncer, por exemplo o de próstata ${ }^{107}$.

Outras atividades importantes também estão relatadas na literatura para a $\beta$-lapachona. Vanni e colaboradores ${ }^{108}$ mostraram que ela induz danos aos cromossomos de células do ovário de hamster chineses (CHO), sugerindo uma interação com a enzima poli(ADPribose)polimerase (PARP). Em estudos recentes, Anderson et al. mostraram que esta quinona tem considerável atividade anticancerígena ( $\mathrm{IC}_{50}: 4-8 \mu \mathrm{M}$ ) em células de mieloma múltipla (malignância hematológica incurável) por apoptose, e que esta atividade está relacionada com a clivagem das enzimas PARP e Caspase- $3^{109}$. Boothman obteve resultados que evidenciam uma ação primordial, mas não independente, de $\mathrm{Ca}^{2+}$ extracelular na indução da apoptose em processo dependente de NQO1 e tendo a $\beta$-lapachona (4a) como substrato ${ }^{110}$. Em estudo recente, Liu demonstrou que a $\beta$-lapachona (4a) inibe a enzima NO-sintase, o que pode abrir novos caminhos para o desenvolvimento de antiinflamatórios de última geração ${ }^{111}$. Aggarwal e colaboradores examinaram a ação da $\beta$-lapachona (4a) sobre o fator de necrose tumoral (TNF) e sugeriram que a indução da apoptose talvez ocorra pela redução de grupos sulfidrilas do $\mathrm{TNF}^{112}$, pois agentes redutores (ex. $\mathrm{N}$-acetilcisteína) revertem o efeito da $\beta$-lapachona. Recentemente, vários pesquisadores relataram que a $\beta$-lapachona (4a) também atua fortemente na indução da apoptose por interferência no complexo topoisomerase II $\alpha$-DNA. Em concentrações menores que $8 \mu \mathrm{M}$, esta substância induziu a morte celular com características de apoptose de células malignas da próstata, o que sugere que esta seja uma substância promissora para a quimioterapia desta doença ${ }^{113}$. Em um estudo sobre a indução da topoisomerase II $^{114}$, com tipos de células sensíveis e resistentes a quimoterápicos, observou-se que esta substância é também citotóxica frente a diferentes células tumorais apresentando, inclusive, atividade sobre células resistentes à camptotecina (12). Este estudo revelou que o envenenamento da topoisomerase II $\alpha$ pela $\beta$-lapachona (4a) é independente do ATP e 
envolve a formação de complexos que podem ser clivados reversivelmente.

A combinação da $\beta$-lapachona (4a) com outras substâncias que atuam em diferentes mecanismos celulares pode ser uma boa alternativa quimioterápica. Pardee e colaboradores ${ }^{115}$ relataram que a $\beta$ lapachona combinada com o taxol, base do fármaco antineoplásico Taxotere ${ }^{\circledR}$ de uso clínico, constitui-se em uma associação muito efetiva contra tumores humanos do ovário e da próstata, implantados em ratos imunossuprimidos, sugerindo uma possível quimioterapia em humanos baseada na combinação destas duas drogas. Recentemente, Kumi-Diaka mostrou que o tratamento combinado da $\beta$ lapachona com a isoflavona genisteina (metabólito obtido da soja) é mais potente para matar células de câncer de próstata PC3 e LNCaP que ambas isoladamente. Como a $\beta$-lapachona atua nos pontos de checagem $\mathbf{G 1}$ e $\mathbf{G 2}$ no ciclo celular, enquanto a genisteina atua nos ponto $\mathbf{G 2}$ e M, a combinação das duas é mais eficiente, mostrando que esta terapia de combinação é mais efetiva para a quimioterapia do câncer de próstata ${ }^{116}$.

\section{ATIVIDADE ANTIVIRAL}

$\mathrm{Na}$ área da virologia, é sabido que a $\beta$-lapachona (4a) e o topotecan (13) inibem seletivamente a replicação do vírus HIV-1, atuando na inibição da enzima LTR $^{117}$. Da mesma forma, 4a é um potente inibidor da enzima transcriptase reversa dos vírus mieloblastose aviária (AMV) e leucemia murina de Rauscher (RLV). Também inibe a $\alpha$-polimerase do DNA. A ação inibitória sobre estas enzimas revelou-se específica se comparada com a de outros inibidores conhecidos ${ }^{118}$.

\section{EFEITO DE RÁDIO-SENSIBILIZAÇÃo}

Até pouco tempo atrás, era consenso entre os terapeutas que os processos clínicos por radioterapia destruíam os tumores por necrose, mas agora se sabe que as células morrem em geral por apoptose. Desta forma, pode-se pensar no uso de substâncias indutoras de apoptose como co-adjuvantes no tratamento do câncer por energia ionizante. Este efeito potencializador da radiação pode diminuir o tempo de exposição durante a terapia, levando a menores efeitos nocivos sobre células normais do corpo humano. Ao que parece, tanto a radiação quanto os inibidores do complexo DNAtopoisomerase provocam danos ao DNA das células cancerosas, por ativação do gene humano p53, que desencadeia a cascata de eventos que levam estas células à apoptose.

Neste sentido, há uma atividade surpreendente da $\beta$-lapachona (4a) - sua ação sinergística em processos de apoptose provocada por radioterapia. $\mathrm{Na}$ década de 80 , foi descoberto que 4 a potencializava a ação rádio-sensibilizadora de alguns derivados pirimidínicos halogenados, aumentando em muito a letalidade das células do carcinoma de laringe quando irradiadas ${ }^{119}$. Mais recentemente, foi descrito que a $\beta$-lapachona (4a), em baixas concentrações, também é rádio-sensibilizadora em vários tipos de células de câncer humano (pulmão, mama, pele e colo-retal). Assim, este efeito de amplificar os efeitos da radiação ionizante terapêutica sugere a utilização desta substância na radioterapia de tumores ${ }^{120,121}$, assim como de outros inibidores da topoisomerase ${ }^{122}$ de características similares ${ }^{123}$, como a camptotecina (12) e o etoposídeo (13).

A presença de vários inibidores de topoisomerase I, na concentração $4 \mu \mathrm{M}$, aumenta significativamente a porcentagem de eficiência da radiação sobre células rádio-resistentes de melanoma humano (U1Mel): camptotecina, 12, 54\%; topotecan, 13, 92\%; $\beta$-lapachona, 4a, $79 \%$; 3-alil- $\beta$-lapachona, (14), 89\%, esta na concentração de $10 \mu \mathrm{M}$. A topotecan (13), 9-amino-camptotecina e a 3-alil- $\beta$-lapachona (14), por terem menor toxicidade sobre células, em estudos in vitro, e por serem potencializadoras mais eficientes da radiação letal, são candidatas a ensaios clínicos futuros.

\section{MODIFICAÇÕES NA CARBONILA DA $\beta$-LAPACHONA (4a)}

Burton e colaboradores ${ }^{124}$ relataram a síntese de monoarilimino $o$-quinonas derivadas da $\beta$-lapachona, na expectativa de modificar o sistema redox. Os derivados fenilimina (18a) e $p$-metilfenilimina (18b) mostraram-se de citotoxicidade e seletividade alvissareiras quando testados in vitro (National Cancer Institute, Bethesda, MD, USA), contra 55 linhagens de células de câncer (Figura 9). Em testes preliminares in vivo, no protocolo "hollow fibre" 125 do NCI, sobre 12 linhagens de células tumorais humanas, as substâncias 18a e 18b causaram a morte celular total, um resultado bem superior ao da $\beta$ lapachona (4a), inativa no mesmo protocolo. Anteriormente, este tipo de modificação da unidade naftoquinônica, com transformação de uma carbonila cetônica numa função imina, já havia sido explorada em quinonas heterocíclicas, onde 19a mostrou possuir atividade in vitro contra certos tipos de tumores sólidos (Figura 10) ${ }^{126}$. Pinto e colaboradores descobriram que a reação da $\beta$-lapachona (4a) com excesso de anilina leva à fenazina $\mathbf{1 8 f}$, provavelmente passando pelo intermediário imina 18a. Esta nova fenazina foi nove vezes mais ativa que o cristal violeta contra a forma infecciosa tripomastigota de $T$. cruzi $^{127}$. Outros derivados heterocíclicos da $\beta$-lapachona (4a), como os de estrutura geral $\mathbf{1 9 b}$, apresentam maior atividade tripanossomicida in vitro que as naftoquinonas correspondentes, com destaque para os que contêm o anel imidazólico (Figura 10) ${ }^{128}$.

Mais recentemente, foi estudada a formação seletiva de derivados imínicos. A hidrazona 18c da $\beta$-lapachona (4a) pode ser obtida seletivamente, em $97 \%$ de rendimento ${ }^{129}$. A oxima $18 d$ também foi obtida com a mesma regiosseletividade ${ }^{130}$. É interessante notar que a regiosseletividade na formação destes produtos, por ataque seletivo de nucleófilos à carbonila da posição 6 do sistema orto-naftopiranodiona, também ocorre na reação de diazotização da $\beta$-lapachona (4a) com tosilidrazina formando o diazocomposto $18 \mathrm{e}^{\mathbf{1 3 1}}$. Embora sejam de fácil síntese, até o momento não se tem muitos relatos sobre possíveis atividades farmacológicas para as substâncias 18c-18e. A maior reatividade da carbonila quinonoídica da posição C-6 não está ainda devidamente explicada. Dois fatores podem contribuir para esta maior reatividade: impedimento estérico na posição 5 , causado pelo grupo $\mathrm{CH}_{2}$ vizinho e menor reatividade de C-5 devido à conjugação da ligação dupla com um oxigênio em posição beta.

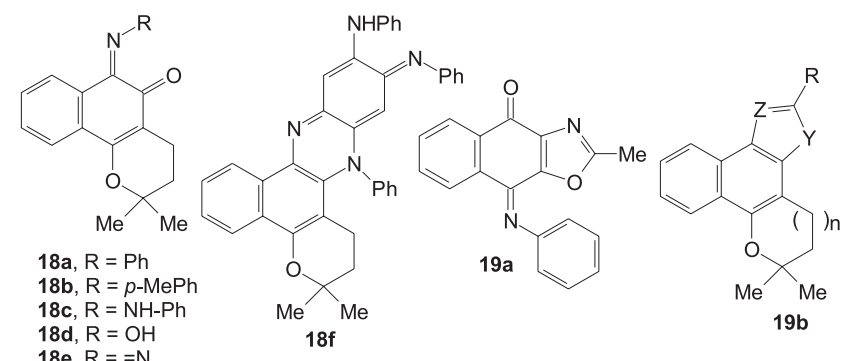

Figura 10. Quinoniminas derivadas da $\beta$-lapachona (4a)

Um resultado bem interessante foi obtido por Frydman e colaboradores $^{132}$, que relataram a reação da $\beta$-lapachona (4a), e de outras orto-naftoquinonas similares com 2-mercaptoetanol (Esquema 2). Os produtos finais foram obtidos por tratamento posterior com $\mathrm{BF}_{3} \cdot \mathrm{Et}_{2} \mathrm{O}$, mas os intermediários só foram observados por $\mathrm{RMN}$ de ${ }^{1} \mathrm{H}$. Na nossa opinião, mesmo a elucidação destas estruturas não foi 
de todo convincente apesar deste trabalho, inequivocamente, mostrar que a $\beta$-lapachona (4a) tem uma forte afinidade por sítios sulfidrílicos, comuns em superfícies de macromoléculas biológicas. Recentemente, Oliveira-Brett e colaboradores ${ }^{133}$, seguindo esta linha de pensamento, mostraram que na redução eletroquímica da $\beta$ lapachona na presença dsDNA e ssDNA não houve danos diretamente no DNA, indicando que a sua atuação é direta nas DNA toposisomerases. A fim de verificar a participação dos resíduos de L-cisteína das toposisomerases no processo de interação $\beta$-lapachonatoposisomerases, foi estudada a voltametria cíclica conjunta da $\beta$ lapachona (e o derivado 3-sulfônico) com a L-cisteína e o 2mercaptoetanol. Os resultados indicaram efeitos dependentes da concentração, indicando uma possível adição tipo 1,2 e 1,4 do grupo tiol na $\beta$-lapachona, reforçando a hipótese de Frydman (Esquema 2).

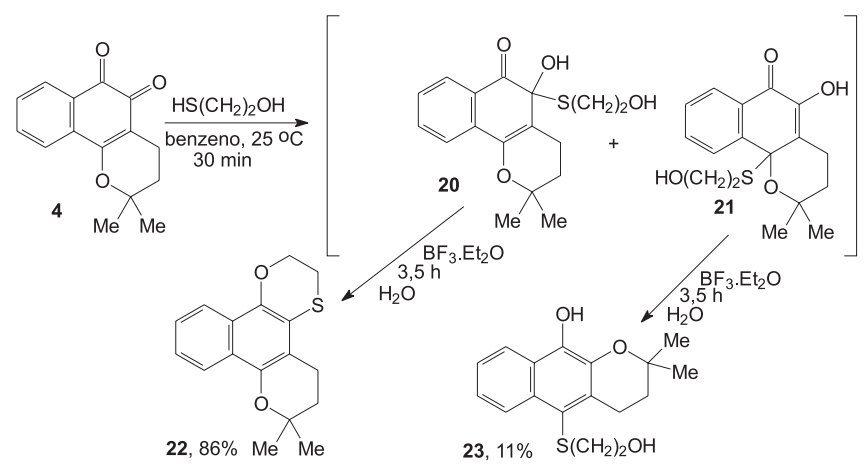

Esquema 2. Reação da $\beta$-lapachona (4a) com 2-mercaptoetanol

Recentemente, salvicina (29), uma naftoquinona de estrutura diterpenóide ${ }^{134}$, constituinte da planta chinesa Salvia prionitis, apresentou forte atividade anticancerígena in vitro e in vivo contra tumores humanos sólidos (Figura 11) ${ }^{135}$. A salvicina (29) tem a mesma potência do etoposídeo (15), agindo contra três tipos de leucemia, além de ser citotóxica frente a células malignas multi-resistentes. Esta atividade foi associada à indução da apoptose, por ação na topoisomerase II $^{136}$. Apesar de não haver ainda uma comparação direta entre os efeitos de 29 com os da $\beta$-lapachona (4), uma atuação biológica muito semelhante de ambas constitui-se em uma boa hipótese.

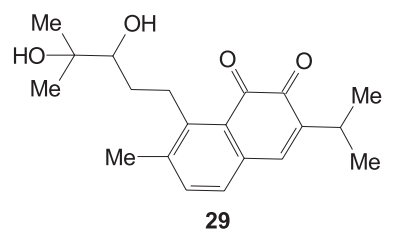

Figura 11. Naftoquinona pirânica bioativa isolada de fonte natural

\section{CONCLUSÃO}

Este trabalho teve por objetivo apresentar aos leitores da área da química uma visão geral sobre as potencialidades de substâncias de estruturas naftoquinonoídicas, em estudos químicos e farmacológicos. Foram enfatizados aspectos relativos ao lapachol (8) e à $\beta$-lapachona (4a).

As características das quinonas mostradas neste trabalho indicaram o quanto ainda existe de potencial nestas substâncias como temas de estudos químicos sintéticos e farmacológicos. Não mais do que um século foi necessário para que químicos e farmacólogos fossem fascinados pela variedade de propriedades destas substâncias. Hoje o ponto máximo destas substâncias encontra-se nos efeitos indutores da apoptose e os desafios que suas propriedades farmacológicas despertam.

É muito significativa a sua propriedade de indução da apoptose, por agirem sobres as enzimas topoisomerases I e II. Até o momento, a bioquímica da indução não está de todo esclarecida. Entretanto, podemos destacar algumas observações para ponderações: 1) a inibição direta da topoisomerase pela $\beta$-lapachona (4a), mesmo antes da adição de DNA como substrato (aumento drástico da inibição); 2) a interação com a topoisomerase I é dependente do sistema enzimático NQO1-redutase; 3) atuação no complexo topo II/DNA, de forma contraposta à camptotecina; 4) promoção da elevação dos níveis intracelulares de $\mathrm{H}_{2} \mathrm{O}_{2}$ e $\left.\mathrm{O}_{2}^{-} ; 5\right)$ inibição, por agentes antioxidantes, da ação da $\beta$-lapachona (4a) sobre enzimas redutoras; 6) modificações estruturais na unidade orto-quinonoídica (ciclo redox) interferem em sua atividade; 7) a $\beta$-lapachona possui ação sinergística tanto na radioterapia quanto em associação com o taxol.

Com as informações disponíveis na literatura pode-se apontar para uma ação de indução da apoptose através da inibição do complexo topoisomerase-DNA. A possibilidade de uma ação direta da $\beta$-lapachona (4a) no ciclo catalítico das enzimas da topoisomerase I e II, assim como a geração endógena de $\mathrm{O}_{2} \cdot \mathrm{e}_{2} \mathrm{O}_{2}$, são sinais decisivos que desencadeiam a apoptose. De todo modo, não se deve considerar a toxicidade elevada desta quinona como um fator limitante ao uso clínico. Novas expectativas colocam-se nos estudos futuros da relação atividade biológica versus estrutura química, uma área de atuação aberta à química medicinal, que pode levar à solução de problemas de toxicidade. As naftoquinonas, de fato, constituem-se em um desafio.

\section{AGRADECIMENTOS}

Os autores gostariam de agradecer as valiosas sugestões e correções dos Profs. A. V. Pinto (NPPN-UFRJ), a quem dedicamos este trabalho, e C. Freitas (IB-UFF). V. F. Ferreira e M. C. B. V. de Souza agradecem ao $\mathrm{CNPq}$ pelas bolsas de produtividade e ao apoio financeiro do CNPq, CAPES e FAPERJ. M. N. da Silva agradece à CAPES pela bolsa de doutorado concedida ao Programa de Pós-Graduação em Química Orgânica da UFF.

\section{REFERÊNCIAS E NOTAS}

1. Thomson, R. H. Em Naturally Occurring Quinones; Academic Press: New York, 1971; Thompson, R. H. Em Naturally Occuring Quinones IV: Recents Advances; Champman \& Hall: London, 1997.

2. Barreiro, E. J.; da Silva, J. E. M.; Fraga, C. A. M.; Quim. Nova 1996, 19, 641.

3. Goodwin, T. W.; Mercer, E.I.; Introduction to Plant Biochemistry, Pergamon Press: New York, 1972.

4. Mahler R. H.; Lordes H. E.; Biological Chemistry, 2nd ed.; Herper International Edition: London, 1971.

5. Matés, J. M.; Sánchez-Jiménez, F. M.; Int. J. Biochem. Cell Biol. 2000, 32, 157 e referências citadas.

6. Rüttimann, A.; Chimia 1986, 40, 290.

7. Morton, R. A.; Biochemistry of Quinones, Academic Press: London,1965; Patai, S.; The Chemistry of the Quinoid Compounds, John Wiley \& Sons: London,1974; Patai, S.; Rappoport, Z.; The Chemistry of the Functional Groups. The Chemistry of the Quinonoid Compounds, John Wiley \& Sons: New York,1988; Thomson, R. H.; Naturally Occurring Quinones IV, Blackie Academic \& Professional: London,1997.

8. Crooke, S. T.; Bradner, W.J.; Cancer Treat. Rev. 1976, 3, 121.

9. Tomasz, M.; Palom, Y.; Pharmacol. Ther. 1991, 76, 71.

10. Pan, S.; Andrews, P. A.; Glover, C. J.; Bachur, N. R.; J. Biol. Chem. 1984, 259, 959.

11. Oliveira, R. B.; Alves, R. J.; Quim. Nova 2002, 25, 976. 
12. Acton, E. M.; Tong, G. L.; Masher, C. W.; Smith, T. H.; Henry, D. W.; J. Med. Chem. 1979, 22, 922.

13. Wilhanson, J.; Scott-Finningan, T. J.; Nature 1981, 292, 466.

14. Kurylowicz, W.; Antibióticos: Uma revisão Crítica, Edufpe: Recife, 1981.

15. Barreiro, E. J.; Fraga, C. A. M.; Química Medicinal: As bases Moleculares da Ação dos Fármacos, Editora Artmed: Porto Alegre, 2001, cap. 2.

16. Ferreira, V. F.; Pinto, A. V.; Pinto, M. C. R.; Santos, S. C.; J. Braz. Chem. Soc. 1996, 7, 169.

17. Costa S. C.; Tese de Mestrado, Universidade Federal do Rio de Janeiro, Brasil, 1990.

18. Henry, D.W.; ACS Symp. Ser. 30; American Chemical Society: Washington D. C., 1976, p. 15.

19. Montanari, C. A.; Bolzani, V. S.; Quim. Nova 2001, 24, 105.

20. Brand, J. D.; Fisher, F. J.; J. Org. Chem. 1990, 55, 2518

21. Salmon-Chemin, L.; Buisine, E.; Yardley, V.; Kohler, S.; Debreu, M.-A.; Landry, V.; Sergheraert, C.; Croft, S. L.; Krauth-Siegel, R. L.; DavioudCharvet, E.; J. Med. Chem. 2001, 44, 548 .

22. Lin, T. S; Antonini, I.; Cosby, L. A.; Sartorelli, A. C.; J. Med. Chem. 2001, $27,813$.

23. Gaudiano, G.; Koch, T. H.; Chem. Res. Toxicol. 1991, 4, 2.

24. Valverde E. M.; Tese de Mestrado, Universidade Federal Fluminense, Brasil, 1996.

25. Pandey, S.K.; Naware, N. B.; Trivedi, P.; Saxena, A. K.; SAR QSAR Environ. Res. 2001, 12, 574.

26. Arnaudon, G.; Compt. Rend. 1858, 46, 1152.

27. Paternó, E.; Gazz. Chim. Ital. 1882, 12, 337.

28. Gibbs, R. D.; Chemotaxonomy of Flowering Plants, University Press: Montreal 1974; Linardi M. C. F.; De Oliveira, M. M.; Sampaio R. P.; J. Med. Chem. 1975, 18, 1159.

29. Ferreira, V. F.; Química Nova na Escola 1996, 4, 35.

30. http://www.pvp.com.br, acessada em Maio 2002.

31. Belizário, J. E.; Ciência Hoje 2002, 31, 50.

32. Amarantes-Mendes, G. P.; Green D. R.; Braz. J. Med. Biol. Res. 1999, 32, 1053; Horta, M. F.; Young, J. D.-E.; Ciência Hoje 1999, 25, 38; Buttke, T. M.; Sandstrom, P. A.; Immunol. Today 1994, 15, 7.

33. Machado, A. E. H.; Quim. Nova 2000, 23, 237.

34. Makin, G.; Dive, C.; Trends Cell Biol. 2001, 11, S-22.

35. Hickman, J. A.; Curr. Opinion Genet. Dev. 2002, 12, 67.

36. Subramanian, S.; Ferreira, M. M. C.; Trsic, M.; Struct. Chem. 1998, 9, 47.

37. Rao, K. V.; Mcbride, T. J.; Oleson, J. J.; Cancer Res. 1968, 28, 1952.

38. Oliveira, A. B.; Zani, C. L.; Raslan, D. S.; Miraglia, M. C. M.; Mesquita, A. L.; Maia, J. G. S.; Quim. Nova 1990, 13, 302.

39. Khan, R. M.; Mlungwana, S. M.; Phytochemistry 1999, 50, 439

40. Kumagai, Y.; Tsurutani, Y.; Shinyashiki, M.; Takeda, S. H.; Nakai, Y.; Yoskikawa, T.; Shimojo, N.; Environ. Toxicol. Pharmacol. 1997, 3, 245; Ferraz, P. A. L.; de Abreu, F. C.; Pinto, A. V.; Glezer, V.; Tonholo, J.; Goulart, M. O. F.; J. Electroanal. Chem. 2001, 507, 275.

41. Molina Portela, M. P.; Fernandez Villamil, S. H.; Perissinotti, L. J.; Stoppani, A. O.; Biochem. Pharmacol. 1996, 52, 1875.

42. Garnier, S.; Wolfender, J.-L.; Nianga, M.; Stoeckli-Evans, H.; Hostettmann, K.; Phytochemistry 1996, 42, 1315; Cortes, M.; Katalinic, J.; Valderrama, J.; An. Quim. 1983, 79, 202.

43. Austin, F. G.; Am. J. Trop. Med. Hyg. 1974, 23, 412; Pinto, A. V.; Pinto, M. C. R.; Gilbert, B.; Pellegrino, J.; Mello, R. T.; Trans. Roy. Soc. Trop. Med. Hyg. 1977, 71,133.

44. Santos A. F.; Ferraz, P. A. L.; Pinto, A. V.; Pinto, M. C. F.R.; Goulart, M O. F.; Sant'Ana, A. E. G.; Int. J. Parasitol. 2000, 30, 1199; dos Santos, A. F.; Ferraz, P. A. L.; de Abreu, F. C.; Chiari, E.; Goulart, M. O. F.; Sant'Ana, A. E. G.; Planta Med. 2001, 67, 92.

45. Teixeira, M. J.; De Almeida, Y. M.; Viana, J. R.; Holanda Filha, J. G.; Rodrigues, T. P.; Prata, J. R. C. Jr.; Coelho, I. C. B.; Rao, V. S.; Pompeu, M. M. L.; Phytoter. Res. 2001, 15, 44.

46. Kayser; O.; Kiderlen, A. F.; Laatsch, H.; Croft, S. L.; Acta Tropica 2000, 77, 307.

47. Goulart, M. O. F.; Zani, C. L.; Tonholo, J.; Freitas, L. R.; Abreu, F. C.; Oliveira, A. B.; Raslan, D. S.; Starling, S.; Chiari, E.; Bioorg. Med. Chem. Lett. 1997, 7, 2043.

48. Para a ação de outros derivados do lapachol e da b-lapachona ver: Pinto, C. N.; Dantas, A. P.; De Moura, K. C. G.; Emery, F. S.; Polequevitch, P. F.; Pinto, M. C. F. R.; De Castro, S. L.; Pinto, A. V.; Arzneim.-Forsch. 2000, 12,1120 .

49. Carvalho, L. H.; Rocha, E. M. M.; Raslan, D. S.; Oliveira, A. B.; Krettli, A. U.; Braz. J. Med. Biol. Res. 1988, 21, 485.

50. Pinto, A. V.; Pinto, M. C. F. R.; Lagrota, M. H. C.; Wigg, M. D.; Aguiar, A. N. S.; Rev. Lat. Amer. Microbiol. 1987, 29,15.

51. Almeida, E. R.; J. Ethnopharmacol. 1990, 29, 239.
52. Santana C. F.; de Lima O. G.; D'albuquerque I. L.; Lacerda A. L.; Martins D. G.; Rev. Inst. Antibiot. (Recife) 1968, 8, 89; Rao, K. V.; Cancer Chemother. Rep. 1974, 4, 11.

53. Goel, R. K.; Pathak, N. K. R.; Biswas, M.; Pandey, V. B.; Sanyal, A. K.; J. Pharm. Pharmacol. 1987, 39,138.

54. Morrison, R. K.; Brown, D. E.; Oleson, J. J.; Cooney, D. A.; Toxicol. Appl. Pharmacol. 1970, 17, 1; Manson, J. M.; Kang, Y. J. Em Principles and Methods of Toxicology; Hayes A. W., ed.; $3^{\text {rd }}$ ed., Raven Press: New York, 1994, p. 989

55. Guerra, M. O.; Mazoni, A. S. B.; Brandão, M. A. F.; Peters, V. M.; Contraception 1999, 60, 305.

56. Weaver, R. J.; Dickins, M.; Burke, M. D.; Biochem. Pharmacol. 1993, 46, 1183.

57. Canfield, C. J.; Pudney, M.; Gutteridge, W. E.; Exp. Parasitol. 1993, 80, 373; Olliaro, P.; Wirth, P. D.; J. Pharm. Pharmacol. 1997, 49, 29.

58. Knecht, W.; Henseling, J.; Löffler, M.; Chem.-Biol. Interact. 2000, 124, 61.

59. Mazunder, A.; Wang, S.; Neamati, N.; Nicklaus, M.; Sunder, S.; Chen, J.; Milne, G.; Rice, W.; Burke, R. T.; Pommer, Y.; J. Med. Chem. 1996, 39, 2472.

60. Ferreira, V. F.; Pinto, A. V.; Silva, J. S.; Gilbert, B.; Rev. Inst. Oswaldo Cruz 1992, 87, 345.

61. Camara, C. A.; Pinto, A. C.; Rosa, M. A.; Vargas, M. D.; Tetrahedron 2001, $57,9569$.

62. Gonçalves de Lima, O.; Albuquerque, I.; Gonçalves de Lima, C.; Maia, M. H.; Rev. Inst. Antibiot. (Recife) 1962, 4, 3

63. Dyaz, F.; Medina, J. D.; J. Nat. Prod. 1996, 59, 423.

64. Dubin, M.; Fernadez Villamil, S. H.; Stoppani, A. O.; Medicina 2001, 61, 343.

65. Gracy, R. W.; Talent, J. M.; Kong, Y.; Conrad, C. C.; Mutat. Res. 1999, $428,17$.

66. Rover Junior, L.; Höehr, N. F.; Vellasco, E. A. P.; Kubota, L. T.; Quim. Nova 2001, 24, 112 e referências citadas.

67. Ramos-Vasconcelos, G.; Alves, A. L. H.; Hermes-Lima, M. Em O Que é Vida; El-Hani, C. N.; Videira, A. A. P., eds.; Relume-Dumará: Rio de Janeiro, 2000, cap. 9

68. Rover Júnior, L.; Höehr, N. F.; Vellasco, E. A. P.; Kubota, L. T.; Quim. Nova 2001, 24, 112 e referências citadas.

69. Fridovisc, I.; J. Exp. Biol. 1998, 201, 1203.

70. Marr, J. J.; Docampo, R.; Rev. Infections Dis. 1986, 8, 884; Goijman, S. G.; Stoppani, A. O. M.; Arch. Biochem. Biophys. 1985, 240, 273.

71. Kappus, H.; Biochem. Pharmacol. 1986, 35, 1; Monks, T. J.; Hanzlik, R. P.; Cohen, G. M.; Ross, D.; Graham, D. G.;Toxicol. Appl. Pharmacol. 1992 112, 2; de Abreu, F. C.; Ferraz, P. A. L.; Goulart, M. O. F.; J. Braz. Chem. Soc. 2002, 13, 19.

72. A reação de Fenton original envolve a oxidação de $\alpha$-hidroxi éster com $\mathrm{H}_{2} \mathrm{O}_{2} \mathrm{FeCl}_{2}$ : Fenton, H. J. H.; Jackson, H.; J. Chem. Soc. 1899, 1.

73. Babior, B. M.; Braz. J. Med. Biol. Res. 1997, 30, 141.

74. Barbouti, A.; Doulias, P.; Zhu, B.; Frei, B.; Galaris, D.; Free Radical Biol. Med. 2001, 31, 490; Bar-Or, D.; Winkler, J. V.; Free Radical Biol. Med. 2002, 32, 197 .

75. Flowers, L.; Ohnishi, S. T.; Penning, T M.; Biochem. 1997, 36, 8640.

76. Beckman, K. B.; Ames, B. N.; J. Biol. Chem. 1997, 272, 19633.

77. Whitacre, C. M.; Zborowska, E.; Gordon, N. H.; Mackay, W.; Berger, N. A.; Cancer Res. 1997, 57,1425.

78. Moloney, G. P.; Kelly, D. P.; Mack, P.; Molecules 2001, 6, 230 e referências citadas.

79. Bassi, L.; Palitti, F.; Genet. Mol. Biol. 2000, 24, 1065.

80. Mathijssen, R. H. J.; Loos, W. J.; Verweij, J.; Sparreboon, A.; Curr. Cancer Drug Targets 2002, 2, 103.

81. Bamford, M.; Walkinshaw, G.; Brown, R.; Exp. Cell Res. 2000, 256, 1.

82. Grabowski, D.; Ganapathi, R.; Ann. New York Acad. Sci. 1996, 803, 306.

83. Wang, J. C.; Annu. Rev. Biochem. 1996, 65, 635.

84. Vários modelos esquemáticos estão descritos na literatura para a visualização do processo inibitório das topoisomerases: Osheroff, N.; Pharmacol. Ther. 1989, 41, 223; Watt, P. M.; Hickson, I. D.; Biochem. J. 1994, 303, 681; Roca, J.; Trends Biochem. Sci. 1995, 20, 156; Berger, J. M.; Gamblim, S. J.; Harrison, S. C.; Wang, J. C.; Nature 1996, 379, 225.

85. Para uma revisão sobre os inibidores catalíticos da topoisomerase II ver: Andoh, T.; Ishida, R.; Biochem. Biophys. Acta 1998, 1400, 155.

86. Tanabe, K.; Ikegami, Y.; Ishida, R.; Andoh, T.; Cancer Res. 1991, 51, 4903.

87. Andoh, T.; Biochime 1998, 80, 235; Roca, J.; Wang, J. C.; Cell 1992, 71, 833

88. Li, Y. Z.; Li, C. J.; Pinto, A. V.; Pardee, A. B.; Mol. Med. 1999, 5, 232.

89. Huang, L.; Pardee, A. B.; Mol. Med. 1999, 5, 711. 
90. Gonçalves, A. M.; Vasconcellos, M. E.; Docampo, R.; Cruz, F. S.; de Souza, W.; Leon, W.; Mol. Biochem. Parasitol. 1980, 1, 167; Pinto, A. V.; Gilbert, B.; Pinto, M. C. R. F.; Ann. Trop. Med. Parasitol. 1978, 72, 523; Goijman, S. G.; Stoppani, A. O. M.; Arch. Biochem. Biophys. 1985, 240, 273; De Moura, K. C. G.; Emery, F. S.; Neves-Pinto, C.; Pinto, M. C.F. R.; Dantas, A. P.; Salomão, K.; de Castro, S. L.; Pinto, A. V.; J. Braz. Chem. Soc. 2001, 12,325 .

91. Molina, M. P.; Stoppani, A. O. M.; Biochem. Pharmacol. 1996, 51, 275.

92. Guiraud, P.; Steiman, R.; Campos Takaki, G.M.; Seigle-Murandi, E.; Simeon, B.M.; Planta Med. 1994, 60, 373.

93. Muller, K.; Seller, A.; Wiegrebe, W.; J. Nat. Prod. 1999, 62, 1134.

94. Boothman, D. A.; Trask, D. K.; Pardee, A. B.; Cancer Res. 1989, 49, 605.

95. Krishnan, P.; Bastow, K. F.; Biochem. Pharmacol. 2000, 60, 1367.

96. Thompson, C. B.; Science 1995, 267, 1456; Barinaga, M.; Science 1998, $280,32$.

97. Chiang, J.; Averboukh, L.; Pardee A. B.; J. Biol. Chem. 1993, 268, 22463.

98. Weller, M.; Winter, S.; Schmidt, C.; Esser, P.; Fontana, A.; Int. J. Cancer 1997, 73, 707; Hueber, A.; Esser, P.; Heimann, K.; Koclok, W.; Weller, S.; Exp. Eye Res. 1998, 67, 525.

99. Wuerzberger, S. M.; Pink, J. J.; Planchon, S. M.; Byers, K. L.; Bornmann, W. G.; Boothman, D. A.; Cancer Res. 1998, 58, 1876.

100. Pink, J. J.; Wuerzberger, S. M.; Tagliarino, C.; Planchon, S. M.; Yang, X.H.; Froelich, C. J.; Boothman, D. A.; Exp. Cell Res. 2000, 255, 144.

101. Li, C. J.; Pardee, A. B.; US pat. 6,245,807 1998; Geiser, A. H.; Witiak, D. T.; Frydman, B. J.; Sun, J. S.; US pat. 5,969,163 1997; ibid US pat. 5,824,700 1996; Pardee, A. B.; Li, C. J.; Crumpacker, C.; Zhang, L.; Eur. Pat. WO9,404,145 1993; Li, C. J.; Li, U.-Z.; Pardee, A. B.; Eur. Pat. WO0,061,142 2000; Witiak, D. T.; Boothman, D. A.; Frydman, B. J.; US pat. 5,763,625 1995; Li, C. J.; Pardee, A. B.; Eur. Pat. WO0,970,8162 1996; Li, C. J.; Pardee, A.; Eur. Pat. WO0,970,7797 1996.

102. Pardee, A. B.; Li, Y. Z.; Li, C. J.; Curr. Cancer Drug Targets 2002, 2, 227.

103. Shiah, S.-G; Chuang, S.-E.; Chau, Y.-T.;Shen, S.-C.; Kuo, M.-L.; Cancer Res. 1999, 59, 391.

104. Chau, Y.-P.; Shiah, S.-G.; Don, M.-J.; Kuo, M.-L.; Free Radical Biol. Med. 1998, 24, 660 .

105. Kiu, T.-J.; Lin, S.-T.; Chau, Y.-P.; Toxicol. Appl. Pharmacol. 2002, 182, 116.

106. Pink, J. J.; Planchon, S. M.; Tagliarino, C.; Varnes, M. E.; Siegel, D.; Boothman, D. A.; J. Biol. Chem. 2000, 275, 5416.

107. Planchon, S. M.; Pink, J. J.; Tagliarino, C.; Bornmann, W. G.; Varnes, M. E.; Boot, D. A.; Exp. Cell Res. 2001, 267, 95.

108. Vanni, A.; Fiore, M.; De Salvia, R.; Cundari, E.; Ricordy, R.; Ceccarelli, R.; Degrassi, F.; Mutat. Res. 1998, 401, 55.

109. Gupta, D.; Podar, K.; Tai, Y.-T.; Lin, B.; Hideshima, T.; Akiyama, M.; LeBlanc, R.; Catley, L.; Mitsiades, N.; Mitsiades, C.; Chauhan, D.; Munshi, N. C.; Anderson, K. C.; Exp. Hematol. 2002, 30, 711.

110. Tagliarino, C.; Pink, J. J.; Dubyak, G. R.; Nieminen, A.-L.; Boothman, D. A.; J. Biol. Chem. 2001, 276, 19150.

111. Liu, S.-H.; Tzeng, H.-P.; Kuo, M.-L.; Lin-Shiau, S.-Y.; Br. J. Pharmacol. 1999, $126,746$.

112. Manna, S. K.; Gad, Y. P.; Mukhopadhyay, A.; Aggarwal, B. B.; Biochem. Pharmacol. 1999, 57, 763
113. Li, C. J.; Wang, C.; Pardee A. B.; Cancer Res. 1995, 55, 3712.

114. Frydman, B.; Marton, L. J.; Sun, S. J.; Neder, K.; Witiak, T. D.; Liu, A. A; Wang, H. M.; Mao, Y.; Wu, H. Y.; Sanders, M. M.; Liu, L. F.; Cancer Res. 1997, 57, 620

115. Li, C. J.; Li, Y.-Z.; Pinto, A. V.; Pardee, A. B.; Proc. Natl. Acad. Sci. U.S.A. 1999, 96, 13369

116. Kumi-Diaka, J.; Biol. Cell 2002, 94, 37.

117. Li, C. J.; Zhang, L. J.; Dezube, B. J.; Crumpacker, C. S.; Pardee, A. B.; Medical Sci. 1993, 90, 1839.

118. Schuerch, A. R; Wehrli, W.; Eur. J. Biochem. 1978, 84, 197.

119. Boothman, D. A.; Greer, S.; Pardee, A. B.; Cancer Res. 1987, 47, 5361; Boothman, D. A.; Trask, D. K.; Pardee, A. B.; Cancer Res. 1989, 49, 605.

120. Boothman D. A.; Pardee, A. B.; Proc. Natl. Acad. Sci. U.S.A. 1989, 86, 4963; Smith, P. J.; Bio Essays 1990, 12, 167.

121. Boothman, D. A.; Greer, S.; Pardee, A. B.; Cancer Res. 1987, 47, 5361; Lamond, J. P.; Kirwin, R.; Wall, M. E.; Boothman, D. A.; Proc. Annu. Meet. Am. Assoc. Cancer. Res. 1995, 36, A2630.

122. Chen, A. Y.; Choy, H.; Rothenberg, M. L.; Oncology-New York 1999, 39.

123. Loprevite, M.; Favoni, R. E.; de Cupis, A.; Pirani, P.; Pietra, G.; Bruno, S.; Grossi, F.; Scolaro, T.; Ardizzoni, A.; Lung Cancer 2001, 33, 27; Kim, J.-S.; Amorino, G. P.; Pyo, H.; Cao, Q.; Choy, H.; Radiother. Oncol. 2002, 62, 61; Amorino, G. P.; Hercules, S. K.; Mohr, P. J.; Pyo, H.; Choy, H.; Int. J. Radiat. Oncol. Biol. Phys. 2000, 47, 503.

124. Di Chenna, P.H.; Benedetti-Doctorovich, V.; Baggio, R. F.; Garland, M. T.; Burton, G.; J. Med. Chem. 2001, 44, 2486.

125. Mi, Q.; Lantvit, D.; Reyes-Lim, E.; Chai, H.; Zhao, W.; Lee, I.-S.; PerazaSánchez, S.; Ngassapa, O.; Kardono, L. B. S.; Riswan, S.; Hollingshead, M. G.; Mayo, J. G.; Farnsworth, N. R.; Cordell, G. A.; Kinghorn, A. D.; Pexxuto, J. M. J. Nat. Prod. 2002, 65, 842.

126. Doctorovich, B. V.; Burgess, E. M. ; Lampropolus, J.; Lednicer, D.; Van Derveee, D.; Zalkow, L. H.; J. Med. Chem. 1994, 37, 710.

127. Neves-Pinto, C.; Malta, V. R. S.; Pinto, M. C. F. R.; Santos, R. H. A.; de Castro, S. L.; Pinto, A. V.; J. Med. Chem. 2002, 45, 2112.

128. Neves-Pinto, C.; Dantas, A. P.; De Moura, K. C. G.; Emery, F. S.; Polequevitch, P. F.; Pinto, M. C. F. R.; de Castro, S. L.; Pinto, A. V.; Arzneim.-Forsch./Drug Res. 2000, 50, 1120.

129. Carvalho, C. E. M.; Ferreira, V. F.; Pinto, A. V.; Pinto, M. C. F. R.; Harrison, W.; Dyes Pigm. 2002, 52, 209.

130. Emery, F. S.; Moura, K. C. G.; Pinto, A. V.; Pinto, M. C. F. R.; Pereira, L. B. A.; Marques, R. A.; Resumos da $24^{a}$ Reunião Anual da Sociedade Brasileira de Química, Poços de Caldas, Brasil, 2001.

131. Ferreira, V. F.; de Souza, M. C. B. V.; da Silva, M. N.; Pinto, A. V.; Br PI 0.200.273-6 2002.

132. Neder, K.; Marton, L. J.; Liu, L. F.; Frydman, N.; Cell. Mol. Biol. 1998, 44,465 .

133. Oliveira-Brett, A. M.; Goulart, M. O. F.; Abreu, F. C.; Bioelectrochemistry 2002, 56, 53 .

134. Zhang, J.-S.; Ding, J.; Tang, Q.-M; Zhao, M. L.-H.; Chen, L.-J.; Yuan, S.T.; Bioorg. Med. Chem. Lett. 1999, 9, 2731.

135. Meng, L.-H.; Zhang, J.-S.; Ding, J.; Biochem. Pharmacol. 2001, 62, 733.

136. Meng, L.-H.; Ding, J.; FEBS Lett. 2001, 501, 50. 